\title{
Prevalence of asymptomatic atherosclerosis of extracranial vessels among hypertensive patients in southern Egypt: An extracranial duplex study
}

Ghaydaa A. Shehata, MD, Lobna Abd-Elwahid, MD, Mohamed Fathy, MSc, Abmed Nasreldein, MD.

\begin{abstract}
الأهداف: لا يزال انتشار تصلب الشرايين في الأوعية الدموية

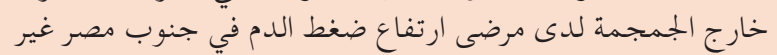

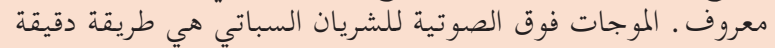

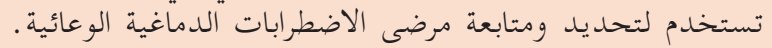

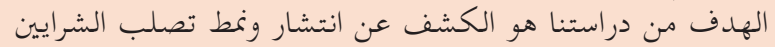

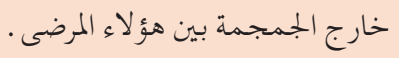

المنهجية : أجريت دراسة الحالات والشواهد الخاصة بنا خلال الفترة

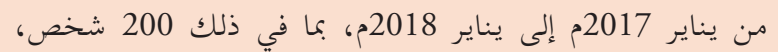

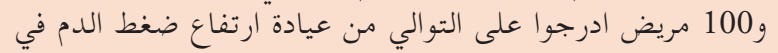

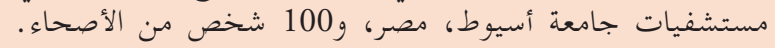

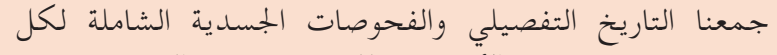

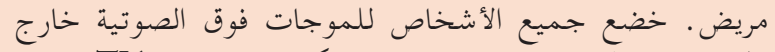

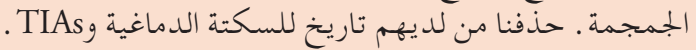

النتائج : كشفنا عن زيادة سماكة الوسط الداخلي في 37 مريضا

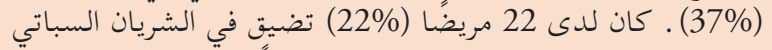

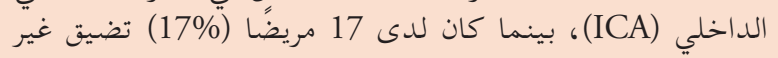

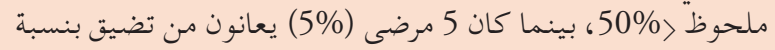

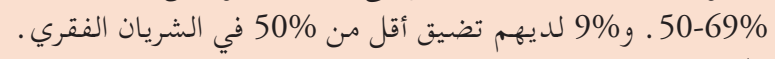

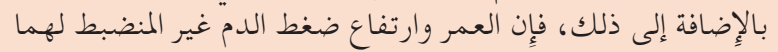

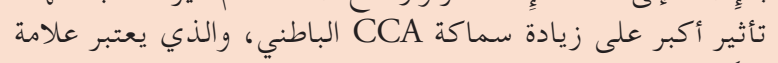
مبكرة لتصلب الشرايين.

الحاتمة : ارتفاع ضغط الدم غير المنضبط هو عامل خطر مهم لتصلب

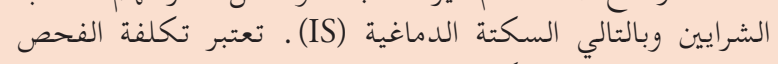

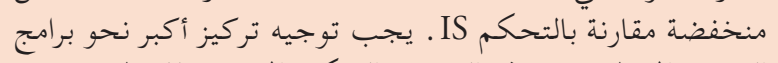

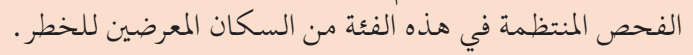

Objectives: The prevalence of atherosclerosis in extracranial vessels among hypertensive patients in southern Egypt is still unknown. Carotid ultrasound is an accurate method used to identify and follow patients with cerebrovascular disorders. The aim of our study is to detect the prevalence and pattern of extracranial atherosclerosis among those patients.

Methods: Our case-control study was performed from January 2017 to January 2018, including 200 subjects, 100 patients recruited consecutively from the Hypertension Clinic in Assiut University hospitals, Egypt, and 100 healthy controls. Detailed history collection and thorough physical examinations were carried out for each patient. All subjects underwent extracranial ultrasound. We omitted patients with history of ischemic stroke and TIAs.

Results: The presence of increased intima media thickness was detected in 37 patients (37\%). 22 patients (22\%) had internal carotid artery (ICA) stenosis, 17 patients $(17 \%)$ had non-significant stenosis $<50 \%$, while five patients $(5 \%)$ had stenosis $50-69 \% .9 \%$ had stenosis $<50 \%$ in vertebral artery. In addition, age and uncontrolled hypertension have a greater impact on increasing the CCA intima media thickness, which is considered an early sign of atherosclerosis.

Conclusions: Uncontrolled hypertension is an important risk factor for atherosclerosis and hence ischemic stroke (IS). The cost of screening is considered low compared to IS management. Greater emphasis should be directed toward regular screening programs in this risky population.

Neurosciences 2020; Vol. 25 (5): 386-391 doi: 10.17712/nsj.2020.5.20200034

From the Department of Neurology and psychiatry (Shehata, Fathy, Nasreldein), Department of Internal Medicine (Abd-Elwahid), Faculty of Medicine, Assiut University, Assiut, Egypt.

Received 3rd May 2020. Accepted 14th June 2020.

Address correspondence and reprint request to: Dr. Mohamed F. Mahmoud, Department of Neurology, Assuit University, Assiut, Egypt. E-mail: Mohamed.fathy19892018@gmail.com

ORCID ID: https://orcid.org/?0000-0002-1316-9628 
$\mathrm{I}$ schemic stroke (IS) is a major health problem that leads to increased morbidity and mortality all over the world. Moreover, IS has very serious economic consequences, both for its management or during post-stroke care. ${ }^{1}$ Reducing the burden of stroke requires identification of the most common modifiable risk factors to control and follow. Hypertension is one of the major modifiable risk factors for IS. ${ }^{2}$ The approximate prevalence rate of hypertension in Egypt was $26.3 \%,{ }^{3}$ and it is more prevalent in the south than in the north of Egypt. ${ }^{3}$ Hypertension leads to atherosclerosis through several mechanisms like vascular endothelial dysfunction, early vascular aging, systemic inflammation and thickening of the basal membrane . ${ }^{4}$ Chronic hypertension accelerates the atherosclerotic process by increasing intraluminal pressure and vessel wall thickness. ${ }^{5}$ Atherosclerosis can lead to IS through progressive stenosis and hence occlusion of the extra or intracranial vessels and or arterio-arterial embolization from an athermanous plaque. ${ }^{6}$ The classification of subtypes of acute ischemic stroke (TOAST Trial), ${ }^{7}$ which established the etiologic classification of IS, found that large-artery atherosclerosis played a significant role in the etiology of IS. The incidence rate of stroke among treated hypertensive patients was 289/100,000 and 363/100,000 among untreated hypertensive patients. ${ }^{8}$ Stroke is more easily prevented than treated, so follow up and early intervention of hypertensive patients could help to prevent the occurrence of IS. Carotid Ultrasound is a cheap and reliable method that enables the early detection and accurate monitoring of the extent and degree of the atherosclerosis of the extracranial vessels. Early identification within risky patients could stop them from developing stroke. Up to our knowledge, no previous studies estimating the prevalence and pattern of atherosclerosis among asymptomatic hypertensive patients were performed in southern Egypt. The aim of our work then is to determine the prevalence of asymptomatic atherosclerosis of extracranial vessels and/or stenosis among hypertensive patients who had no other risk factors, previous history of IS or transient ischemic attack (TIA) within the Assiut Governorate in southern Egypt.

Methods. A quasi-experimental design was utilized in this study to estimate the causal effects of an

Disclosure. Authors have no conflict of interests, and the work was not supported or funded by any drug company. intervention on a target population, with the lack of randomization. This study was a case-control study and was conducted from January 2017 to January 2018.

The study protocol was approved by the Ethical Committee of Faculty of Medicine, Assuit University and followed the principles described in the Helsinki Declaration. A written consent was taken from subjects included in the current study before their participation. We examined 200 persons. 100 patients with isolated hypertension without any other risk factors were consecutively enrolled from a hypertension outpatient clinic at Assuit University Hospitals with 100 matched age and sex healthy controls without any vascular risk factor. Inclusion criteria were patients above 18 years old and those diagnosed as isolated hypertension.

Exclusion criteria were history of any cardiac disease (e.g., ischemic heart disease IHD, cardiac arrhythmia and cardiomyopathy), dyslipidemia, DM, Smoking, IS and or TIA.

Patient characteristics such as age, sex, hypertension, control of hypertension and duration of illness were gathered from all the cases included in the study. (According to ESH guidelines, hypertensive patient was defined as a patient with systolic blood pressure $140 \mathrm{mmHg}$ or above and/or diastolic blood pressure $90 \mathrm{mmHg}$ or above, measured in at least two different occasions) or if a patient was previously known to have taken antihypertensive drugs. ${ }^{10}$ Uncontrolled hypertension is defined as patient with systolic blood pressure $140 \mathrm{mmHg}$ or more and/or diastolic blood pressure $90 \mathrm{mmHg}$ or more in spite of being on antihypertensive treatment strategy. ${ }^{10}$

All cases and control groups underwent extracranial carotid and vertebral arteries duplex ultrasound on both sides of the neck including the anterior circulation; common carotid artery (CCA), internal carotid artery (ICA), external carotid artery (ECA) and posterior circulation including both vertebral arteries and their 3 parts (V0, V1, V2). Each studied vessel of the carotid and vertebral vessels was assessed for peak systolic velocity (PSV), end diastolic velocity (EDV) in $\mathrm{cm} / \mathrm{sec}$, and CCA intima medial thickness (IMT) measurement on both sides. CCA IMT $>0.1 \mathrm{~cm}$ was considered abnormal. Detailed extracranial ultrasound examination was conducted with a colour-coded duplex ultrasonography device (Philips HDI 3000). A high-frequency (5- to $10-\mathrm{MHz}$ ) linear probe was used to assess carotid and vertebral arteries on both sides. Carotid artery stenosis and atherosclerosis were identified and quantified according to the Consensus Panel Grey-Scale and Doppler US Criteria for Diagnosis of ICA Stenosis. ${ }^{11}$

Technique. The technique started from the lateral border of sternocleidomastoid muscle at root of neck 
Table 1 - General patients characteristics:

\begin{tabular}{|c|c|c|c|}
\hline \multirow[t]{2}{*}{ Variables } & $\begin{array}{c}\text { HTN } \\
(\mathbf{n}=100)\end{array}$ & $\begin{array}{l}\text { Control } \\
(\mathrm{n}=100)\end{array}$ & P.value \\
\hline & \multicolumn{2}{|c|}{ n (\%) } & \\
\hline \multicolumn{4}{|l|}{ Age } \\
\hline From 30 to 39 years & $14(14)$ & $12(12)$ & 0.932 \\
\hline From 40 to 49 years & $22(22)$ & $38(38)$ & 0.060 \\
\hline From 50 to 59 years & $39(39)$ & $36(36)$ & 0.858 \\
\hline From $>60$ to 70 years & $25(25)$ & $14(14)$ & 0.181 \\
\hline Mean \pm SD & $51.35 \pm 10.09$ & $49.22 \pm 8.09$ & 0.196 \\
\hline \multicolumn{4}{|l|}{ Gender } \\
\hline Male & $31(31)$ & $42(42)$ & 0.249 \\
\hline Female & $69(69)$ & $58(58)$ & 0.248 \\
\hline \multicolumn{4}{|l|}{ Hypertension } \\
\hline Controlled & $43(43)$ & - & - \\
\hline Uncontrolled & $57(57)$ & - & - \\
\hline Duration of illness (year) & $5.56 \pm 4.22$ & - & - \\
\hline \multicolumn{4}{|c|}{$\begin{array}{l}\text { Data described as number and percentages or mean } \pm \text { Standard } \\
\text { deviation according to need. Chi-square test used to compare } \mathrm{Nu} \& \% \text {, } \\
\text { Independent Simple T test used to compare means } \pm \mathrm{SD} \text {; Hypertension } \\
\text { was defined as a blood pressure } \geq 140 / 90 \mathrm{~mm} \mathrm{Hg} \text { for } \geq 2 \text { repeated } \\
\text { measurements }\end{array}$} \\
\hline
\end{tabular}

while the patient was in the supine position with their head turned to one side. A high-frequency linear phased array probe was placed, starting at the proximal segment of the CCA. Scanning of the CCA, carotid bulb, and both the ICA and ECA was done in the longitudinal and transverse planes, while scanning of both vertebral arteries was carried out in the longitudinal plane only. The CCA and ICA were scanned in grayscale and with colour Doppler. ${ }^{12,13}$

Statistical analysis. Data analyses were performed with the IBM SPSS version 20.0 software. The data were tested for normality using the Kolmogorov-Smirnov test and for homogeneity variances prior to additional statistical analysis. Categorical variables were described by number and percent (N, \%) values, whereas continuous variables were described by mean and standard deviation (Mean, SD) values. The chi-square test was used to compare between categorical variables (Table 1, e.g., age groups, sex), while continuous variables were compared using the independent-samples t test. Pearson's ( $\mathrm{r}$ ) correlation was used to test the correlation between 2 continuous variables (Figure 1), but Spearman's test was used to evaluate one continuous variable and one categorical variable (Figure 2). A two-tailed $p<0.05$ was considered statistically significant.

Results. Patients characteristics. We studied 200 persons, including 100 patients and 100 controls. The

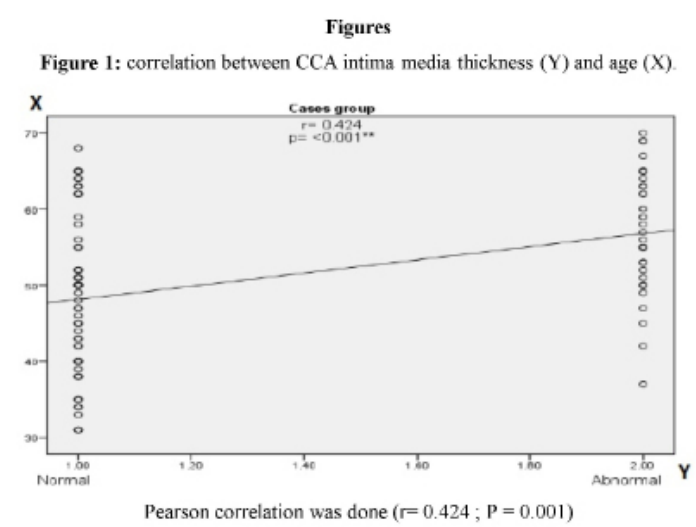

Figure 1 - Correlation between carotid intima media thickness and age.

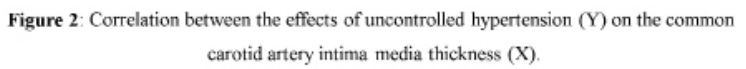
carotid artery intima media thickness (X).

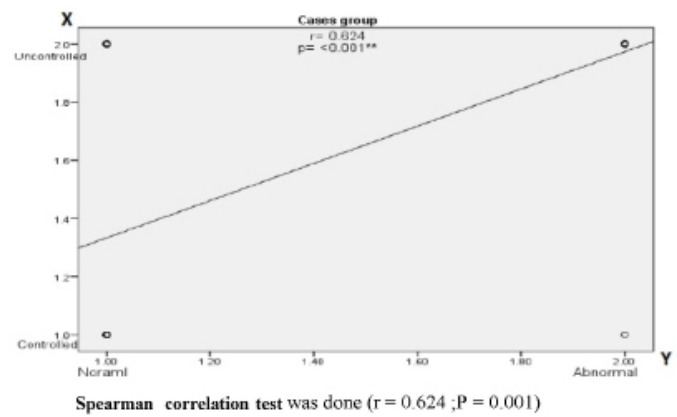

Figure 2 - Correlation between the effects of uncontrolled hypertension on the common carotid artery intima media thickness.

patient group included 31 males and 69 females, while the control group included 42 males and 58 females without any statistically significant difference between both groups.

The mean age was $51.35 \pm 10.09$ for the hypertensive group and $49.22 \pm 8.09$ for the control group. Among 100 cases with hypertension, $45 \%$ were controlled hypertension, and $55 \%$ were uncontrolled hypertension. The duration of hypertension ranged from 2 years to 12 years, and the mean duration of illness was $5.56 \pm 4.22$ (Table 1).

Among the hypertensive group, $37 \%$ of patients had increased CCA intima media thickness, 26\% had unilateral increase in IMT and $11 \%$ had bilateral increased IMT, while $12 \%$ of the control group had increased CCA IMT (unilateral only) (Table 2). 
Table 2 - Results of common carotid artery intima media thickness measurement in 100 cases with hypertension. ( $\mathrm{n}=100)$ and control group ( $\mathrm{n}=100)$.

\begin{tabular}{|c|c|c|c|c|c|c|c|}
\hline \multirow{2}{*}{$\begin{array}{l}\text { Cases } \\
\mathrm{N}=100\end{array}$} & \multicolumn{2}{|c|}{ Gender } & \multicolumn{2}{|c|}{ Control of hypertension } & \multirow{2}{*}{$\begin{array}{c}\text { Cases } \\
\mathrm{n}=100\end{array}$} & \multirow{2}{*}{$\begin{array}{l}\text { Control } \\
\mathrm{n}=100 \\
\text { (0) }\end{array}$} & \multirow[t]{2}{*}{ P.value } \\
\hline & Male & female & Controlled & Uncontrolled & & & \\
\hline Abnormal intima media thickness & 13 & 24 & 1 & 36 & $37(37)$ & $12(12)$ & $0.001^{* *}$ \\
\hline Unilateral increased CCA intima media thickness & 7 & 19 & 0 & 26 & $26(26)$ & $12(12)$ & $0.019^{*}$ \\
\hline Bilateral increased CCA intima media thickness & 6 & 5 & 1 & 10 & $11(11)$ & 0 & -- \\
\hline
\end{tabular}

Table 3 - Frequency of different degrees of carotid atherosclerosis among asymptomatic hypertensive patients.

\begin{tabular}{|c|c|c|c|c|c|c|c|c|}
\hline \multirow[b]{2}{*}{$\begin{array}{l}\text { Total number of cases } \\
\mathbf{n}=(100)\end{array}$} & \multirow[b]{2}{*}{$\begin{array}{c}\text { Total cases } \\
\mathrm{n}=100\end{array}$} & \multirow[b]{2}{*}{$\begin{array}{l}\text { Control } \\
\text { group } \\
\mathrm{n}=100\end{array}$} & \multicolumn{2}{|c|}{ Gender } & \multicolumn{4}{|c|}{ Control of hypertension } \\
\hline & & & $\begin{array}{l}\text { Male } \\
\mathrm{n}=31\end{array}$ & $\begin{array}{l}\text { Female } \\
\mathrm{n}=69\end{array}$ & P-Value & $\begin{array}{c}\text { Uncontrolled } \\
\text { hypertension } \\
N=57\end{array}$ & $\begin{array}{c}\text { Controlled } \\
\text { hypertension } \\
\mathbf{n}=43\end{array}$ & P-Value \\
\hline$<50 \% \%$ stenosis & $17(17)$ & 0 & $6(35.3)$ & $11(64.7)$ & 0.085 & $13(76.5)$ & $4(23.5)$ & 0.003 \\
\hline from $50 \%: 69 \%$ stenosis & $5(5)$ & 0 & 1 & 4 & - & 5 & 0 & - \\
\hline
\end{tabular}

Table 4 - Frequency of different degrees of vertebral artery atherosclerosis among asymptomatic hypertensive patients.

\begin{tabular}{lcccccc}
\hline \multirow{2}{*}{ Total number of cases $(\mathbf{n}=\mathbf{1 0 0})$} & \multicolumn{2}{c}{ Gender } & \multicolumn{2}{c}{ Control of hypertension } & Cases & Control group $\mathbf{n}=100$ \\
\cline { 2 - 5 } & Male & Female & controlled & Uncontrolled & $(\mathbf{n}=\mathbf{1 0 0 )}$ & Cos \\
\hline Cases with less than 50\% stenosis & 1 & 8 & 4 & 5 & $9(9 \%)$ & 3 \\
Cases with more than 50\% stenosis & 0 & 0 & - & - & 0 & 0 \\
\hline
\end{tabular}

The discrepancy between both groups was statistically significant as the mean and standard deviation of the CCA IMT was $0.09 \pm 0.03$ in the patient group and $0.08 \pm 0.01$ in the control group with a significant difference between the two groups $(p=0.001)$ (Table 2). Our results also showed that $22 \%$ of cases in the hypertension group had asymptomatic stenosis in ICA, $17 \%$ of them had stenosis less than $50 \%$ in ICA, while $5 \%$ of them had stenosis between $50-69 \%$ of ICA, while no patients among our study group had stenosis $\geq 70 \%$. The results showed a strong correlation between uncontrolled hypertension and severity of atherosclerosis of the extracranial vessels. 13 cases $(76.5 \%)$ of patients with less than $50 \%$ stenosis and $100 \%$ of patients with stenosis $50-69 \%$ had uncontrolled hypertension. Our results also showed that the hypertensive females revealed a higher tendency to develop ICA stenosis in comparison to males. $64.7 \%$ of cases with less than $50 \%$ stenosis of ICA and $80 \%$ of cases with stenosis $50-69 \%$ were females. Regarding the control group $(n=100)$, none of them exhibited ICA stenosis, which demonstrates the effect of hypertension on causing ICA stenosis in comparison with the non-hypertensive group (Table 3).

Table 4 showed that among 100 cases with hypertension, $9 \%$ had less than $50 \%$ stenosis of the V0 segment of the vertebral artery, which was the most common site for stenosis. Female gender and uncontrolled hypertension carry greater risk for stenosis than for those with male gender and controlled hypertension. The control group $(\mathrm{n}=100)$ showed only 3 cases with less than $50 \%$ stenosis (3\%). Neither cases nor control groups had more than $50 \%$ stenosis of the vertebral artery (V0) segment.

Pearson correlations were calculated, and Spearman tests were done to examine the relations between different factors with CCA IMT. The correlative results showed that age $(\mathrm{r}=0.424 ; p=0.001)$ (Figure 1) and uncontrolled hypertension ( $\mathrm{r}=0.624 ; p=0.001)$ (Figure 2) were the most factors strongly positive correlated with increased IMT.

Discussion. In our study, we aimed to detect asymptomatic atherosclerosis in extracranial vessels among asymptomatic hypertensive patients who had no other risk factors like (DM, dyslipidaemia, smoking and Cardiovascular problems). In our study, $37 \%$ of hypertensive patients had increased CCA IMT. 22\% of hypertensive patients had asymptomatic stenosis in ICA. Also, about $17 \%$ had stenosis $<50 \%$ in ICA, 
while $5 \%$ of them had stenosis between $50-69 \%$ of ICA. $9 \%$ of hypertensive patients had $<50 \%$ stenosis at V0 segment of the vertebral artery. None of hypertensive patients in our study had $\geq 70 \%$ stenosis of the ICA nor $>50 \%$ stenosis in the vertebral artery. These findings suggest that atherosclerotic changes in the anterior circulation are more prevalent among our patients than posterior circulation. Increased carotid IMT is the most common consequence among our hypertensive patients, and severe carotid and vertebral artery stenosis or occlusion are absent among our asymptomatic patients. The uncontrolled hypertension (Blood pressure $\geq 140 / 90 \mathrm{mmHg}$ in spite of being on anti-hypertensive treatments ${ }^{10}$ and age were the most predominant risk factors for occurrence of asymptomatic atherosclerosis and stenosis.

Our results were in concordance with Chien et $\mathrm{al}^{14}$ who examined the impact of hypertension and dyslipidaemia on the carotid IMT and found that hypertension had a positive effect on CCA IMT, even more than dyslipidaemia. Zhao and colleagues ${ }^{15}$ examined CCA IMT in hypertensive patients lasting 4 years and found that increased IMT was the most predominant result of hypertension. Grau and colleagues $^{16}$ studied 3161 individuals to analyse the effect of the different cardiovascular risk factors on IMT; they found that the age and blood pressure were the main determining factors for carotid intima-media thickness in both sexes, which was also similar to the results found in our study and is already known and expected.

We found that hypertensive females had significantly higher rates of increased IMT and carotid stenosis compared to males. This finding is similar to the results published by Curcio who found that hypertension had a higher impact in female arterial properties and characteristics like arterial stiffness, Pulse wave velocity, Pulse wave travel distance, beat to beat diameter waveform and IMT. ${ }^{17}$ Also, Kaul $S^{18}$ found a higher prevalence of asymptomatic increased IMT among women $(7.4 \%)$ compared to men $(4.0 \%)$. Contrary to our results, Loboz-Rudnicka ${ }^{19}$ found IMT values to be lower in women than in men, which was most obvious above the age of 45 years. She also found that IMT in men is mostly affected by age, while in females, it is mostly affected by age and blood pressure. The positive effect of age and uncontrolled hypertension on CCA IMT was also found in our results; however, the higher prevalence of increased IMT among our female subjects could be explained by the conservative pattern of life in southern Egypt, where most females are housewives, do not work and stay in the home most of the time.

Lack of physical exercise and inability to perform regular hospital visits to control their blood pressure made them more vulnerable to atherosclerotic changes. Elwan and colleagues ${ }^{20}$ studied 80 Egyptian subjects with different metabolic syndrome status and no history of cerebrovascular accidents. They divided their patients into 2 groups: group 1 (62.5\%) was diagnosed with metabolic syndrome (DM, hypertension and dyslipidaemia), and group $2(37.5 \%)$ did not exhibit any type of metabolic syndrome. Extracranial carotid duplex ultrasound examination revealed plaques with low grade stenosis ( $<50 \%$ stenosis) in $19(38 \%)$ patients in group 1 and only 4 patients (13.3\%) in group 2 $(p=0.02)$, while the mean IMT was $0.09 \mathrm{~cm}$ in group 1 and $0.08 \mathrm{~cm}$ in group $2(p=0.053)$. These findings are similar to our results, because we found that the mean IMT was $0.09 \pm 0.03$ in the hypertensive group and $0.08 \pm 0.01$ in the control group. Contrary to our results, none of the subjects involved in their study showed $>50 \%$ stenosis of the ICA.

Abdallah and his colleagues ${ }^{21}$ studied extracranial carotid artery disease in 4,733 Egyptians using carotid ultrasound. $27.6 \%$ of their study population were diabetic, $38.8 \%$ were hypertensive, $5.2 \%$ were IHD and $3.5 \%$ had dyslipidemia. They found that $17.6 \%$ of the study population had IMT thickening, $1.7 \%$ had $50-69 \%$ stenosis, $0.8 \%$ had stenosis $\geq 70 \%$ and $0.06 \%$ only had total occlusion on the ICA. Again, their results were in concordance with the results of our study, as increased IMT was the most frequent atherosclerotic change observed among their patients, and they found low prevalence rates of high-grade carotid stenosis. The absence of high-grade stenosis among our subjects in contrary to previous studies could be attributed to the absence of the other cardiovascular risk factors among our subjects as our patients only exhibited hypertension. It also seems that the prevalence of significant carotid stenosis among Egyptian subjects is much lower than that observed in researches from other populations, like in USA, Europe and Asia. ${ }^{22,23}$ Our results are also concordant with Milio et $\mathrm{al}^{24}$ who found that the prevalence of increased IMT was higher in hypertensive patients (66.5\%) compared to normal persons (23.5\%); however, his findings were higher than our prevalence rates $(37 \%$ of our hypertensive patients had increased IMT), and this could be attributed to his relatively higher age group (mean age $62.7 \pm 12$ vs. $51.35 \pm 10.09$ in our study)) and lower cut-off level of the IMT $(\geq 0.9$ $\mathrm{mm}$ vs. $>1 \mathrm{~mm}$ ) compared to our study. In addition, racial differences could have an important role in the severity and of carotid atherosclerosis.

Limitations of the study. The first limitation in our study was the small sample size used in this study is the most important limitation and can be attributed to 
our inclusion criteria, since we selected asymptomatic isolated hypertensive patients without any other risk factors or history of stroke and TIA, which was difficult to find. The second limitation of the present study was that it is a hospital-based study and not a populationbased study, which may be considered to be a more reliable indicator of true disease patterns.

In conclusion, Uncontrolled hypertension is an important risk factor for atherosclerosis, even among asymptomatic patients. Progressive atherosclerosis can lead to IS. Since, the cost of screening is considered low in comparison to IS management, greater emphasis should be directed toward regular screening programs for risky populations.

Acknowledgment. Thanks for patients and for American Manuscript editors for language editing.

\section{References}

1. Collaborators GBDN. Global, regional, and national burden of neurological disorders, 1990-2016: a systematic analysis for the Global Burden of Disease Study 2016. Lancet Neurol 2019; 18: 459-480.

2. O'Donnell MJ, Xavier D, Liu L, Zhang H, Chin SL, RaoMelacini P, et al. Risk factors for ischaemic and intracerebral haemorrhagic stroke in 22 countries (the INTERSTROKE study): a case-control study. Lancet 2010; 376: 112-123.

3. Hasan DM, Emeash AH, Mustafa SB, Abdelazim GE, El-din AA. Hypertension in Egypt: a systematic review. Curr Hypertens Rev 2014; 10: 134-141.

4. Chen R, Ovbiagele B, Feng W. Diabetes and Stroke: Epidemiology, Pathophysiology, Pharmaceuticals and Outcomes. Am J Med Sci 2016; 351: 380-386.

5. Niiranen TJ, Kalesan B, Hamburg NM, Benjamin EJ, Mitchell GF, Vasan RS. Relative Contributions of Arterial Stiffness and Hypertension to Cardiovascular Disease: The Framingham Heart Study. J Am Heart Assoc 2016; 5.

6. Banerjee C, Chimowitz MI. Stroke Caused by Atherosclerosis of the Major Intracranial Arteries. Circ Res 2017; 120: 502-513.

7. Adams HP, Jr., Bendixen BH, Kappelle LJ, Biller J, Love $\mathrm{BB}$, Gordon DL, et al. Classification of subtype of acute ischemic stroke. Definitions for use in a multicenter clinical trial. TOAST. Trial of Org 10172 in Acute Stroke Treatment. Stroke 1993; 24: 35-41.

8. Li C, Engstrom G, Hedblad B, Berglund G, Janzon L. Blood pressure control and risk of stroke: a population-based prospective cohort study. Stroke 2005; 36: 725-730.

9. Carpenter M, Sinclair H, Kunadian V. Carotid Intima Media Thickness and Its Utility as a Predictor of Cardiovascular Disease: A Review of Evidence. Cardiol Rev 2016; 24: 70-75.

10. Mancia G, Fagard R, Narkiewicz K, Redon J, Zanchetti A, Bohm M, et al. 2013 ESH/ESC guidelines for the management of arterial hypertension: the Task Force for the Management of Arterial Hypertension of the European Society of Hypertension (ESH) and of the European Society of Cardiology (ESC). Eur Heart J 2013; 34: 2159-2219.
11. Grant EG, Benson CB, Moneta GL, Alexandrov AV, Baker JD, Bluth EI, et al. Carotid artery stenosis: gray-scale and Doppler US diagnosis--Society of Radiologists in Ultrasound Consensus Conference. Radiology 2003; 229: 340-346.

12. Oates CP, Naylor AR, Hartshorne T, Charles SM, Fail T, Humphries $\mathrm{K}$, et al. Joint recommendations for reporting carotid ultrasound investigations in the United Kingdom. Eur J Vasc Endovasc Surg 2009; 37: 251-261.

13. Polak JF. Carotid ultrasound. Radiol Clin North Am 2001; 39: 569-589.

14. Chien KL, Tu YK, Hsu HC, Su TC, Lin HJ, Chen MF, et al. Differential effects of the changes of LDL cholesterol and systolic blood pressure on the risk of carotid artery atherosclerosis. BMC Cardiovasc Disord 2012; 12: 66.

15. Zhao XX, Liu J, Zhao H, Zhou Y, Li L, Wang H. The effect of cardiovascular risk factors on the carotid intimamedia thickness in an old-aged cohort with hypertension: a longitudinal evolution with 4-year follow-up of a random clinical trial. Clin Exp Hypertens 2019; 41: 49-57.

16. Grau M, Subirana I, Marrugat J, Elosua R. Percentiles of carotid intima-media thickness in a Spanish population with and without cardiovascular risk factors. Rev Esp Cardiol (Engl Ed) 2013; 66: 749-751.

17. Curcio S, Garcia-Espinosa V, Castro JM, Peluso G, Marotta M, Arana M, et al. High Blood Pressure States in Children, Adolescents, and Young Adults Associate Accelerated Vascular Aging, with a Higher Impact in Females' Arterial Properties. Pediatr Cardiol 2017; 38: 840-852.

18. Kaul S, Alladi S, Mridula RK, Bandaru SVCS, Boddu DB, Anjanikumar D, et al. Prevalence and risk factors of carotid intima-media thickness in asymptomatic individual subjects in a tertiary care center in India. Ann Indian Acad Neurol 2015; 18: 430-434.

19. Loboz-Rudnicka M, Jaroch J, Bociaga Z, Rzyczkowska B, Uchmanowicz I, Polanski J, et al. Impact of cardiovascular risk factors on carotid intima-media thickness: sex differences. Clin Interv Aging 2016; 11: 721-731.

20. Elwan S, Tawfik TZ, Assal HS, El-Jaafary S, Hegazy MM, Tawfik S, et al. Prevalence of Cerebral Atherosclerosis among Patients with Metabolic Syndrome: A Case Control Study on Egyptian Subjects. World Journal of Cardiovascular Diseases 2016; 6: 8-13.

21. Abd Allah F, Baligh E, Ibrahim M. Clinical relevance of carotid atherosclerosis among Egyptians: a 5-year retrospective analysis of 4,733 subjects. Neuroepidemiology 2010; 35: 275-279.

22. Fine-Edelstein JS, Wolf PA, O'Leary DH, Poehlman H, Belanger AJ, Kase CS, et al. Precursors of extracranial carotid atherosclerosis in the Framingham Study. Neurology 1994; 44: 1046-1050.

23. O'Leary DH, Polak JF, Kronmal RA, Kittner SJ, Bond MG, Wolfson SK, Jr., et al. Distribution and correlates of sonographically detected carotid artery disease in the Cardiovascular Health Study. The CHS Collaborative Research Group. Stroke 1992; 23: 1752-1760.

24. Milio G, Corrado E, Sorrentino D, Muratori I, La Carrubba S, Mazzola G, et al. Asymptomatic carotid lesions and aging: Role of hypertension and other traditional and emerging risk factors. Arch Med Res 2006; 37: 342-347. 